\section{Nävusassoziierte Melanome weniger aggressiv}

\author{
Melanome, die sich de novo entwickeln, sind offenbar mit einer kürzeren \\ Überlebenszeit assoziiert als Formen, die aus melanozytären Nävi entstehen. \\ Das lässt die Befundauswertung zweier großer US-Kohorten vermuten.
}

Eür ür ihre Studie nutzten Dermatologen aus den USA die Daten der Kohorten NYU1 ( $\mathrm{n}=1.024)$ und NYU2 ( $\mathrm{n}=1.125)$, sodass sie die in der einen Kohorte entdeckten Assoziationen in der zweiten überprüfen konnten. Patienten der ersten Kohorte wurden zwischen 1972 und 1982 im Zentrum aufgenommen und behandelt. Das Follow-up endete 1993. In der zweiten Kohorte wurden die Patienten zwischen 2002 und 2009 aufgenommen, mit einem Follow-up bis 2013. Zwischen dem Zeitpunkt, zu dem der letzte Patient in NYU1 aufgenommen wurde, und dem Zeitpunkt, zu dem der erste $\mathrm{Pa}$ tient in NYU2 aufgenommen wurde, liegen somit zwei Dekaden. Von mehr als 400 klinischen und pathologischen $\mathrm{Pa}$ rametern fokussierten die Ärzte auf elf und zehn Parameter, etwa Alter, Geschlecht, Tumordicke und -lokalisation sowie Gesamtüberleben. In der ersten Gruppe waren die Melanome bei 19,3\% der Patienten nävusassoziiert, in der zweiten Gruppe bei 31,0\%.

Bekannte prognostische Faktoren wie Alter, Tumordicke, Ulzeration, mitotischer Index und Lokalisation des Melanoms am Körperstamm waren in beiden Kohorten signifikant mit dem Überleben assoziiert. So war bei Patienten der NYU2-Kohorte mit De-novo-Melanomen die Wahrscheinlichkeit, kürzer zu leben als Patienten der Vergleichsgruppe mit nävusassoziierten Melanomen, zweieinhalbfach erhöht (Hazard Ratio [HR]: 2,52; $95 \%$-Konfidenzintervall $1,78-3,56 ; \mathrm{p}<0,001)$. In der anderen Kohorte war die Wahrscheinlichkeit, früher zu sterben, weniger stark erhöht (HR: 1,63; 95\%-KI 1,22-2,18; p < 0,001).

Mithilfe einer multivariaten Analyse, in der unter anderem Tumordicke und -lokalisation sowie Ulzerationen bei der Berechnung berücksichtigt wurden, entpuppte sich in der NYU2-Gruppe eine
De-novo-Entstehung als unabhängiger prognostischer Faktor für ein geringeres Überleben (HR: 1,70; 95 \%-KI 1,19-2,44; $\mathrm{p}=0,004)$. In beiden Kohorten war bei Patienten mit De-novo-Melanomen das Überleben von Männern kürzer als von Frauen. Eine Assoziation zwischen Geschlecht und Überleben ließ sich dagegen aus den Befunden der Patienten mit nävusassoziierten Melanomen nicht ablesen. Der beobachtete Unterschied zwischen den Geschlechtern beim Parameter Überleben könnte nach Ansicht der Ärzte auf immunologischen Unterschieden beruhen sowie auf unterschiedlichen Effekten der Geschlechtshormone auf den Hauttumor. Möglicherweise seien zudem nävusassoziierte Melanome aufgrund ihres Geno- und Phänotyps weniger aggressiv.

Fazit: Patienten mit De-novo-Melanomen haben eine schlechtere Prognose als Patienten mit nävusassoziierten Melanomen.

Peter Leiner

Cymerman RM et al. De Novo vs NevusAssociated Melanomas: Differences in

Associations With Prognostic Indicators and

Survival. J Natl Cancer Inst 2016; 108: pii: djw121

\title{
Hinter dem Exanthem steckt ein brasilianisches Virus
}

Ein 39-jähriger Mann suchte wegen einer fiebrigen Erkrankung mit Kopf-, Schluck- und Muskelschmerzen, einer Konjunktivitis und einem Ausschlag im Gesicht eine Nothilfe auf. Begleiterkrankungen waren nicht bekannt. Bei der Untersuchung zeigten sich ein schmetterlingsförmiges Exanthem im Gesicht und eine konjunktivale Injektion (Abb. a) sowie ein makulöses Exanthem im Bereich von Brust und Abdomen (Abb. b). Im Bereich des harten Gaumens fanden sich eine Rötung und petechiale Blutungen (Abb. C). Hinter dem linken Ohr tastete man einen druckdolenten, verschieblichen und weichen Lymphknoten von etwa 15 $\mathrm{mm}$ Durchmesser (Abb. d). Darüber hinaus fielen multiple kleinere, submandibuläre und zervikale Lymphknoten beidseits auf.
Im Routinelabor bestanden keine Auffälligkeiten, im Urinstatus eine leichte Hämaturie.

Der Patient lebte in einer deprivierten Region von Rio de Janeiro. Serologische Untersuchungen auf Dengue, Zytomegalie, Toxoplasmose, EBV, Lues und HIV waren negativ, wie auch eine PCR für Dengue und Chikungunya. Erst die wegen einer Infektionswelle angelegte PCR von Zikavirus-RNA erbrachte ein positives Ergebnis. Die Therapie war symptomatisch. 14 Tage nach der Vorstellung war der Patient vollständig beschwerdefrei. Prof. Hermann Füeßl

Brasil P et al. Exanthema associated with Zika virus infection. Lancet Infect Dis 2016; 16: 866
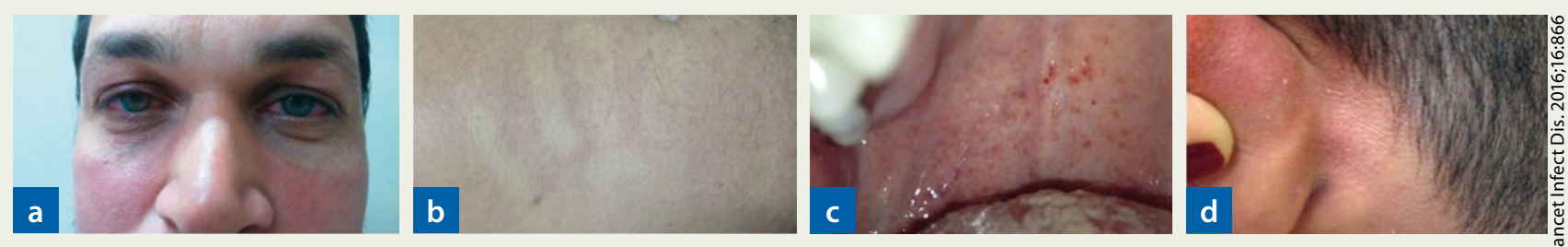

a: Exanthem im Gesicht, konjunktivale Injektion; b: Exanthem am Abdomen; c: Petechiale Blutungen am harten Gaumen; d: Druckdolenter Lymphknoten hinter dem Ohr 